\title{
Macroscopic complete resection is not associated with improved survival in patients with malignant pleural mesothelioma
}

Hasan Fevzi Batirel, MD, PhD, ${ }^{\mathrm{a}}$ Muzaffer Metintas, MD, ${ }^{\mathrm{b}}$ Hale Basak Caglar, MD, ${ }^{\mathrm{c}}$ Guntulu Ak, MD, Perran Fulden Yumuk, MD, ${ }^{\mathrm{d}}$ Rengin Ahiskali, MD, ${ }^{\mathrm{e}}$ Emine Bozkurtlar, MD, ${ }^{\mathrm{e}}$ Nural Bekiroglu, PhD, ${ }^{\mathrm{f}}$ Tunc Lacin, MD, PhD, ${ }^{a}$ Bedrettin Yildizeli, MD, ${ }^{a}$ and Mustafa Yuksel, $\mathrm{MD}^{\mathrm{a}}$

\section{ABSTRACT}

Objective: Macroscopic complete resection (MCR) is the recommended surgical strategy in malignant pleural mesothelioma. Our objective was to analyze whether MCR influences survival in malignant pleural mesothelioma.

Methods: Between 2002 and 2016, 154 patients underwent pleurectomy decortication $(n=90)$, extrapleural pneumonectomy $(n=42)$, or exploratory/diagnostic procedures $(\mathrm{n}=22)$ in a single institution. Patient data were recorded in a prospective database. Patients who underwent surgical resection $(n=132)$ were analyzed according to MCR as a whole group and after propensity score matching based on gender, age, histology, clinical $\mathrm{T}$ and $\mathrm{N}$ status, adjuvant chemotherapy, and trimodality treatment. Kaplan-Meier survival and univariate and multivariate analyses were performed.

Results: Median age was 56 years (range, 26 to 80 years) and 62 were women. One hundred ten had epithelioid histology. MCR was achieved in 75 patients $(49 \%)$ ). In-hospital mortality was seen in 7 patients $(4.5 \%)$. Preoperative chemotherapy was applied in 32 patients. One hundred thirty-three patients underwent adjuvant treatment (45 had chemoradiation). Mean follow-up was $21 \pm 19$ months. Overall median survival, 2-year, and 5-year survivals were 18.1 months, $36 \%$, and $16 \%$, respectively. There was no difference in median survival between patients who underwent MCR (21.4 months) and who did not (16.3 months) $(P=.6)$. Following propensity score matching (23 patients in each group), median survivals were similar (13.3 vs 14.2 months; $P=.63$ ).

Conclusions: MCR was not associated with improved survival in malignant pleural mesothelioma. We need to clearly define MCR and identify subgroups of patients who would benefit from this principle because minimal versus extensive and location of gross residual disease may have different influences on survival. (J Thorac Cardiovasc Surg 2018;155:2724-33)

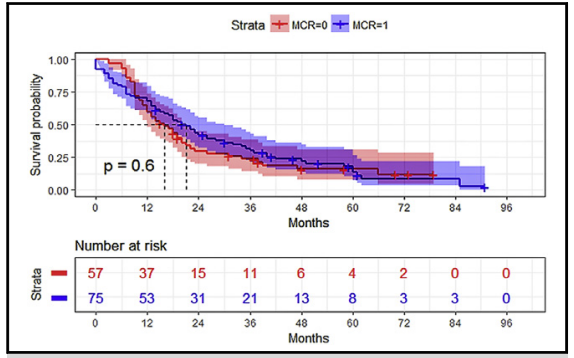

There is no difference in 5 -year survival between patients with MCR and non-MCR.

\section{Central Message}

Macroscopic complete resection is the strategy in malignant pleural mesothelioma. In our study, it was not associated with improved survival. We need to clearly define macroscopic complete resection.

\section{Perspective}

The surgical principle in malignant pleural mesothelioma is macroscopic complete resection. Our study shows that there is no difference in long-term survival in patients with or without macroscopic complete resection. We need to define macroscopic complete resection because size and location of residual tumor may have different influences on survival.

See Editorial Commentary page 2734.
From the ${ }^{\mathrm{a}}$ Department of Thoracic Surgery, ${ }^{\mathrm{d}}$ Division of Medical Oncology, Department of Internal Medicine, ${ }^{\mathrm{e}}$ Department of Pathology, and ${ }^{\mathrm{f}}$ Department of Biostatistics, Marmara University, Istanbul, Turkey; ${ }^{b}$ Lung and Pleural Cancers Research and Clinical Center, Osmangazi University, Eskisehir, Turkey; and ${ }^{c}$ Department of Radiation Oncology, Medipol University, Istanbul, Turkey.

Read at the 97th Annual Meeting of The American Association for Thoracic Surgery, Boston, Massachusetts, April 29-May 3, 2017.

Received for publication April 25, 2017; revisions received Nov 15, 2017; accepted for publication Dec 23, 2017; available ahead of print March 3, 2018.

Address for reprints: Hasan Fevzi Batirel, MD, PhD, Thoracic Surgery Department, Marmara University Hospital, 7 Kat, Gogus Cerrahisi, Fevzi Cakmak Mah, Mimar Sinan Cad, No 41, Ust Kaynarca, Pendik, Istanbul 34899, Turkey (E-mail: hbatirel@marmara.edu.tr).

0022-5223/\$36.00

Copyright (c) 2018 by The American Association for Thoracic Surgery

https://doi.org/10.1016/j.jtcvs.2017.12.131
The main principle in malignant pleural mesothelioma (MPM) surgery is macroscopic complete resection (MCR). This principle was endorsed in 2012 by a multidisciplinary panel of experts. ${ }^{1}$ The recommendations were

Scanning this $\mathrm{QR}$ code will take you to a supplemental video. To view the AATS Annual Meeting Webcast, see the URL next to the webcast thumbnail. 


\section{Abbreviations and Acronyms \\ $\mathrm{CT}=$ Computed tomography \\ EPD $=$ extended pleurectomy and decortication \\ $\mathrm{EPP}=$ extrapleural pneumonectomy \\ IMRT $=$ intensity-modulated radiation therapy \\ MCR $=$ macroscopic complete resection \\ MPM = malignant pleural mesothelioma \\ PD = pleurectomy and decortication \\ PET $=$ positron emission tomography}

published in 2013 and 2 of these focused on MCR and 1 on the techniques to achieve MCR.

The first recommendation stated that surgical MCR and control of micrometastatic disease played a vital role in the multimodality therapy of MPM, as is the case for other solid malignancies. The second recommendation stated that surgical cytoreduction was indicated when MCR was deemed achievable. The choice for type of surgery-extrapleural pneumonectomy (EPP) or pleurectomy and decortication (PD) - was left at the discretion of the surgeon depending on clinical factors and individual surgical judgment and expertise. ${ }^{1}$

These conclusions were based on International Association for the Study of Lung Cancer database that included 3101 patients from 1995 to $2009 .^{2}$ There was a significant survival difference between patients who underwent curative intent surgery and those who had palliative procedures and median survival rates were 18 and 12 months, respectively. Of the 2316 staged cases, diagnostic procedures, partial PD, PD, and EPP were performed in 669, 60, 299, and 1191 patients, respectively. So this survival difference was based on an EPP-predominant database with only $16 \%$ of patients undergoing any form of PD. ${ }^{2}$

Our group and a group from United Kingdom ${ }^{3,4}$ have shown that shifting from an EPP-predominant practice to a PD-predominant practice did not cause any disadvantage in survival. ${ }^{3,4}$ In our study, similar survival outcome was achieved in patients with MPM, despite an almost 2-fold increase in macroscopically incomplete resections. ${ }^{3}$

In a 2011 consensus report, MCR was defined as removal of all grossly visible and palpable tumor and $90 \%$ of respondents believed EPP could achieve this goal. This approval rate dropped to $68 \%$ for extended PD and $23 \%$ for a PD. ${ }^{5}$ However, other authors defined MCR as tumor residual $<1 \mathrm{~cm} .{ }^{6,7}$ Thus there is significant variability within published series in terms of MCR in MPM.

Despite pre-, intra-, and postoperative treatment efforts, there is an obvious stagnation in median survival rates for MPM over the past decade, which is commonly between 18 and 24 months. In 2 recent EPP studies that have more than 500 patients, median survivals following EPP were 18 months with $15 \%$ 5-year survival rates. ${ }^{8,9}$
In our current study, our primary aim was to analyze the influence of MCR on survival of MPM and the secondary aim was to identify favorable subgroups that would benefit from MCR.

\section{METHODS}

One hundred fifty-four patients evaluated for multimodality treatment with histologically proven MPM and who underwent surgery in Marmara University Hospital during 2003 to 2016 were included in the study. For final analysis, patients who underwent diagnostic exploratory procedures were excluded and a cohort of 132 patients were evaluated for MCR. The Ethical Council of Marmara University approved the study.

All patients with radiologically resectable MPM and no bulky mediastinal or extrapleural lymph node metastasis were evaluated for multimodality treatment and surgery to perform MCR. Patients underwent thoracoabdominal computed tomography (CT) scan, positron-emission tomography (PET)-CT scan, laboratory and pulmonary function tests, and cardiac evaluation.

Mediastinal staging was based on CT findings until 2005 and afterward on PET-CT. If there was any suspicious mediastinal lymph node involvement, cervical mediastinoscopy was performed. Magnetic resonance imaging was also used in case of suspicion of involvement beyond the pleural envelope.

The treatment strategy before August 2011 was to perform EPP (with ipsilateral diaphragm and/or pericardial resection), adjuvant high dose hemithoracic irradiation either with 3-dimensional conformal or intensity-modulated radiation therapy (IMRT), and chemotherapy. ${ }^{10}$ After August 2011, our treatment intent was to perform extended pleurectomy and decortication (EPD). After EPD, patients received adjuvant chemotherapy and only prophylactic incisional radiation was applied and hemithoracic irradiation was reserved for subsequent locoregional failure. The strategy of delaying hemithoracic irradiation for patients with MCR was mainly due to the possibility of achieving distant and local control with chemotherapy while avoiding the potential lung toxicities that might be associated with radiation.

\section{Evaluation of MCR}

Two groups were formed: MCR and non-MCR. MCR was defined as no macroscopically visible or palpable tumor following surgical resection. If diaphragm was not removed and the diaphragmatic pleura looked normal, we considered it as MCR. If grossly visible or palpable tumor (whatever the size) was left behind, the method was recorded as partial PD.

The 2 groups were compared for age, gender, side, types of surgical procedures, preoperative chemotherapy, histology, preoperative forced expiratory volume in 1 second, postoperative mortality, hospital stay, clinical T and $\mathrm{N}$ status, pathologic $\mathrm{T}$ and $\mathrm{N}$ status, number of lymph nodes sampled, follow-up, adjuvant chemotherapy or chemoradiation, and sites of recurrence.

To balance the baseline characteristics, we also performed a propensity score matching based on age, gender, histology, clinical $\mathrm{T}$ and $\mathrm{N}$ status, adjuvant chemotherapy, trimodality treatment, and follow-up time.

A retrospective analysis was performed from a prospective database. Survivals were calculated from the date of the operation and updated as of September 2017.

\section{Adjuvant Treatment and Follow-up Strategies}

In patients whom macroscopic tumor was left behind, adjuvant chemotherapy and hemithoracic irradiation was performed. As adjuvant chemotherapy, patients received a total of 4 to 6 courses of adjuvant chemotherapy. Platinum-based combination chemotherapy was administered. Until 2005, gemcitabine was the second agent in the combination; after 2005 , pemetrexed was used. Cisplatinum $75 \mathrm{mg} / \mathrm{m}^{2}$ at day 1 or 
carboplatinum area under the curve 5 at day 1 , gemcitabine $1000 \mathrm{mg} / \mathrm{m}^{2}$ at days 1 and 8 , or pemetrexed $500 \mathrm{mg} / \mathrm{m}^{2}$ at day 1 were given every 3 weeks for a total of 4 courses.

Adjuvant radiotherapy was delivered using photons by a dual energy ( 6 and $18 \mathrm{mV}$ ) linear accelerator. A minimum total dose of photons fields of $54 \mathrm{~Gy}(1.8 \mathrm{~Gy} /$ fraction, 1 fraction per day, 5 days per week) was delivered to the hemithorax, the thoracotomy incision, and sites of chest drains. A boost dose of $9 \mathrm{~Gy}$ was considered for patients who had residual disease marked by surgical clips with photon fields.

Bimodality treatment was accepted as surgery and adjuvant chemotherapy. Prophylactic incisional radiation was not accepted as a treatment modality. Trimodality treatment was accepted as surgery, pre- or postoperative chemotherapy and hemithoracic irradiation. Irradiation was accepted as a modality in the trimodality approach if it was high-dose hemithoracic irradiation with IMRT technique following PD.

Following surgery, patients were seen every 3 months during the first 2 years and every 6 months after 2 years. A chest and abdominal CT scan was performed every 6 months or at any time point if there was a suspicion for recurrence. PET-CT scanning was performed if there was evidence of local or distant metastasis.

Locoregional recurrence was defined as any recurrence in the same hemithorax. Distant metastases were accepted as metastasis to contralateral chest cavity, lung, abdomen, bone, and liver. In non-MCR patients, the location of remaining tumors were noted in the operation notes. Progression of remaining tumor tissue was also handled as locoregional recurrence because it meant the disease could not be kept under control with chemotherapy or radiation.

\section{Statistical Analysis}

Factors influencing survival in the MCR and non-MCR patients were evaluated with univariate and multivariate analysis using IBM-SPSS version 20.0 software (IBM-SPSS Inc, Armonk, NY). Statistical analysis was performed using Kaplan-Meier Survival analysis, log rank test, Student $t$ test, and $\chi^{2}$ test.

\section{RESULTS}

One hundred fifty-four patients (92 men; median age, 56 years [range, 26-80 years and interquartile range, 4862 years]) underwent surgical intervention for MPM during this period. The last follow-up date was September 1, 2017. Only 1 patient was lost to follow-up at 3 months; this patient underwent exploratory thoracotomy with an eventual diagnosis of sarcomatoid subtype. Epithelioid histology was evident in 110 patients $(71 \%)$. Mean number of lymph node stations sampled in N0 patients was $4.7 \pm 3.5$ (median, 4 node stations [range, 1-2 node stations]). Thirty-two patients $(21 \%)$ received preoperative chemotherapy. Fortyfive patients $(29 \%)$ had postoperative chemoradiation and 88 patients $(57 \%)$ received adjuvant chemotherapy. So $86 \%$ of patients received adjuvant treatment (133 out of 154). Overall median survival in 154 patients was 18.1 months $(95 \%$ confidence interval [CI], 14.222 months) and 2- and 5-year survivals were $36 \%$ and $16 \%$, respectively.

Twenty-two patients had exploratory and diagnostic procedures without any resection attempt and thus were excluded from MCR versus non-MCR analysis. MCR was achieved in 75 ( $49 \%$ of the whole cohort) patients and non-MCR in 57 patients.

\section{Influence of MCR on Survival}

The final cohort consisted of 132 patients. Median survival was 18.3 months (95\% CI, 14.5-22.1 months) with 2 - and 5-year survivals of $37 \%$ and $16 \%$, respectively.

Non-MCR patients had more partial PD, shorter hospital stay, higher clinical $\mathrm{T}$ status, surgical/pathologic $\mathrm{T}$ stage, more unexplored nodal status, higher rate of adjuvant chemotherapy, and more frequent locoregional recurrence (Table 1). There was a tendency toward lower postoperative mortality rate in non-MCR patients.

Median survivals of MCR and non-MCR patients were 21.4 months (95\% CI, 16.3-26.5 months) and 16.3 months (95\% CI, 11.2-21.4 months), respectively $(P=.6)$. Twoyear survival rate was $42 \%$ and $30 \%$, respectively, and 5 -year survival rate was $16 \%$ in both groups (Figure 1).

The propensity score-matched cohort consisted of 23 patients in both groups. Median survivals of MCR and nonMCR patients were 13.3 months (95\% CI, 4.5-22.1 months) and 14.2 months (95\% CI, 11.9-16.6 months), respectively $(P=.63)$. Two-year survival rate was $30 \%$ and $24 \%$, respectively, and 5-year survival rate was $15 \%$ and $0 \%$, respectively (Figure 2).

In patients with epithelioid histology $(\mathrm{n}=94)$, overall median survival was 20.9 months ( $95 \%$ CI, $15.8-26$ months) and 2 - and 5-year survivals were $45 \%$ and $21 \%$, respectively. In patients with clinical N0 status and epithelioid histology $(n=69)$, overall median survival was 25.9 months and 2 - and 5 -year survivals were $53 \%$ and $27 \%$, respectively. In patients with pathologic N0 status and epithelioid histology $(\mathrm{n}=51)$ overall median survival was 30.1 months and 2- and 5-year survivals were $60 \%$ and $28 \%$, respectively.

MCR was not associated with improved survival rate in the overall cohort, in patients with epithelial histology, or in the subgroup of patients with epithelioid histology and clinical N0 status (Figure 1 and Figure 3, $A$ and $B$ ).

Fifty-nine patients (79\%) in the MCR group recurred and median time to recurrence was 16.6 months $(95 \% \mathrm{CI}, 10.8$ 22.4 months).

In MPM, 3 years has been defined as long-term survival by Sugarbaker and colleagues ${ }^{10}$ and Table 2 shows the rate of 3-year survivors in MCR patients, non-MCR patients, and in those who underwent only diagnostic exploratory procedures.

\section{Univariate and Multivariate Analysis of the MCR and Non-MCR Cohort}

Univariate analysis showed that age, histology (epithelioid, 20.9 months; biphasic, 14.5 months; and sarcomatoid, 6.2 months; $P<.001$ ), clinical T stage (T1, 84.8 months; T2, 26 months; T3, 15.6 months; and T4 8.6 months; $P=.002$ ), clinical N stage (N0, 22 months; N1, 14.3 months; and N2, 10.8 months; $P=.0015$ ), and surgical/pathologic T stage 
TABLE 1. Comparison of perioperative variables in patients undergoing macroscopic complete resection $(\mathrm{MCR})(\mathrm{n}=75)$ and patients not undergoing MCR $(n=57)$

\begin{tabular}{|c|c|c|c|}
\hline Cohort criteria & $\begin{array}{c}\text { MCR } \\
(n=75)\end{array}$ & $\begin{array}{c}\text { Non-MCR } \\
(\mathbf{n}=\mathbf{5 7})\end{array}$ & $\begin{array}{c}P \\
\text { value }\end{array}$ \\
\hline Mean age & $54 \pm 10$ & $57 \pm 10$ & .12 \\
\hline $\begin{array}{l}\text { Gender } \\
\text { Female } \\
\text { Male }\end{array}$ & $\begin{array}{l}35(47) \\
40(53)\end{array}$ & $\begin{array}{l}20(35) \\
37(65)\end{array}$ & .25 \\
\hline $\begin{array}{l}\text { Side } \\
\text { Right } \\
\text { Left }\end{array}$ & $\begin{array}{l}41(55) \\
34(45)\end{array}$ & $\begin{array}{l}38(67) \\
19(33)\end{array}$ & .29 \\
\hline $\begin{array}{l}\text { Surgical procedures } \\
\text { EPP } \\
\text { EPD } \\
\text { PD } \\
\text { Partial PD }\end{array}$ & $\begin{array}{l}38 \\
19 \\
18 \\
-\end{array}$ & $\begin{array}{r}4 \\
1 \\
5 \\
47\end{array}$ & $<.001$ \\
\hline Preoperative chemotherapy & $13(17)$ & $16(28)$ & .21 \\
\hline $\begin{array}{l}\text { Histology } \\
\text { Epithelioid } \\
\text { Mixed } \\
\text { Sarcomatoid/desmoplastic }\end{array}$ & $\begin{array}{c}58(77) \\
16 \\
1\end{array}$ & $\begin{array}{c}36(63) \\
18 \\
3\end{array}$ & .2 \\
\hline $\begin{array}{l}\text { Forced expiratory volume in } \\
1 \mathrm{~s}(\mathrm{~L})\end{array}$ & $2.14 \pm 0.51$ & $2.13 \pm 0.63$ & .95 \\
\hline 30/90-d mortality & $6 / 11$ & $0 / 2$ & .07 \\
\hline Length of hospital stay (d) & $9.4 \pm 4.3$ & $7 \pm 2.3$ & $<.001$ \\
\hline $\begin{array}{l}\text { Clinical T status } \\
\text { T1 } \\
\text { T2 } \\
\text { T3 } \\
\text { T4 }\end{array}$ & $\begin{array}{r}4 \\
36 \\
32 \\
3\end{array}$ & $\begin{array}{r}0 \\
9 \\
38 \\
10\end{array}$ & $<.001$ \\
\hline $\begin{array}{l}\text { Clinical N status } \\
\text { N0 } \\
\text { N1 } \\
\text { N2 }\end{array}$ & $\begin{array}{r}58 \\
9 \\
8\end{array}$ & $\begin{array}{r}34 \\
14 \\
9\end{array}$ & .08 \\
\hline $\begin{array}{l}\text { Surgical/pathologic T status } \\
\text { T1 } \\
\text { T2 } \\
\text { T3 } \\
\text { T4 }\end{array}$ & $\begin{array}{r}7 \\
39 \\
29 \\
0\end{array}$ & $\begin{array}{r}2 \\
12 \\
38 \\
5\end{array}$ & $<.001$ \\
\hline $\begin{array}{l}\text { Pathologic N status } \\
\text { N0 } \\
\text { N1 } \\
\text { N2 } \\
\text { Nx }\end{array}$ & $\begin{array}{r}7 \\
39 \\
29 \\
0\end{array}$ & $\begin{array}{r}21 \\
9 \\
0 \\
27\end{array}$ & .005 \\
\hline $\begin{array}{l}\text { Number of lymph nodes } \\
\text { sampled }\end{array}$ & $5 \pm 3.1$ & $4 \pm 5$ & .35 \\
\hline Mean follow-up (mo) & $25.3 \pm 22.1$ & $21.8 \pm 18.3$ & .33 \\
\hline $\begin{array}{l}\text { Adjuvant treatment } \\
\text { Chemotherapy } \\
\text { Chemoradiation }\end{array}$ & $\begin{array}{l}26 \\
33\end{array}$ & $\begin{array}{l}40 \\
12\end{array}$ & .005 \\
\hline
\end{tabular}

TABLE 1. Continued

\begin{tabular}{lccc}
\hline \multicolumn{1}{c}{ Cohort criteria } & $\begin{array}{c}\text { MCR } \\
(\mathbf{n}=\mathbf{7 5})\end{array}$ & $\begin{array}{c}\text { Non-MCR } \\
(\mathbf{n}=\mathbf{5 7})\end{array}$ & $\begin{array}{c}\boldsymbol{P} \\
\text { value }\end{array}$ \\
\hline Sites of recurrence & & & \\
$\quad$ Locoregional & 28 & 42 & .002 \\
Distant & 12 & 1 & \\
Locoregional and distant & 18 & 6 & \\
\hline
\end{tabular}

Values are presented as mean \pm standard deviation, $\mathrm{n}(\%)$, or $\mathrm{n}$. Statistically significant values are in italics. $M C R$, Macroscopic complete resection; $E P P$, extrapleural pneumonectomy; $E P D$, extended pleurectomy, decortication; $P D$, pleurectomy and decortication; $N x$, mediastinal lymph nodes not surgically evaluated.

(T1, 65.7 months; T2, 18.1 months; T3, 18.3 months; and T4, 9 months; $P=.04$ ) were significantly associated with survival (Table 3). Gender, side, MCR, pathologic N stage, and treatment (chemotherapy vs chemoradiation) did not cause any significant difference in median survival $(P=.62, P=.57, P=.59, P=.14$, and $P=.33$, respectively).

Stepwise forward logistic regression was performed. Histology and clinical T stage remained significant (Table 3).

\section{DISCUSSION}

MPM is a disease with very poor prognosis and multidisciplinary teams, including thoracic surgeons, try every modality to reverse the fatal outcome of this disease. In almost all series, epithelioid histology and absence of extrapleural lymph node metastasis were the most favorable prognostic factors. ${ }^{8,9,11,12}$ In several EPP and PD series, MCR was also found to be an important determinant of survival. ${ }^{12,13}$ In this study, we tested if MCR was associated with improved survival in our experience of 13 years. Our study failed to show any association between MCR and survival in MPM patients. In our series, 11 patients in the non-MCR group (11 out of 57 [19\%]) survived longer than 3 years, which was exactly the same as the reported literature using MCR techniques. ${ }^{10}$ We also failed to identify any favorable subgroups for MCR because the survivals were not significantly different in patients who had epithelioid histology or in those who had epithelioid histology and clinically not involved lymph nodes.

In a recent retrospective multicenter Italian study of 1365 patients, ${ }^{14}$ median survivals were not different in patients who were younger than age 70 years with epithelioid histology and who received EPP, PD, and only chemotherapy (20.9, 24.6, and 18.6 months, respectively; $P=.596)$. The Mesothelioma-Video-Assisted Thoracic Surgery trial also showed an equivalent survival between video-assisted thoracoscopic surgery partial PD versus talc pleurodesis in MPM patients with 1-year survival rates of $52 \%$ and $57 \%$, respectively. ${ }^{15}$ Our 1 -year survival rate in 132 patients was $65 \%$. 


\section{Strata $+M C R=0+M C R=1$}
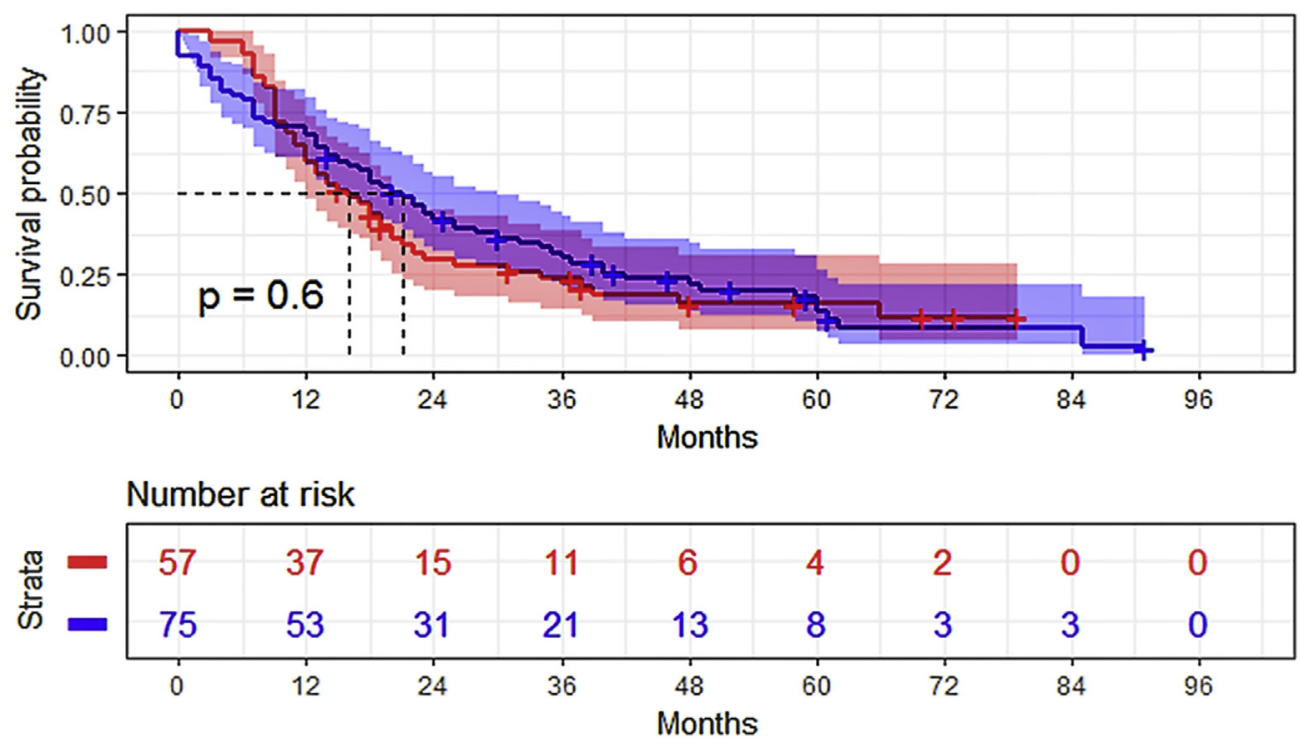

FIGURE 1. Survival curve of patients undergoing macroscopic complete resection $(M C R)$ or not. Overall median survivals were 21.4 moths $(95 \%$ confidence interval, 16.3-26.5 months) and 16.3 months (95\% confidence interval, 11.2-21.4 months), respectively $(P=.6)$. Two-year survival rate was $42 \%$ and $30 \%$, respectively, and 5 -year survival rate was $16 \%$ in both groups.

\section{Strata + PropensitymCR $=0+$ PropensitylMCR $=1$}

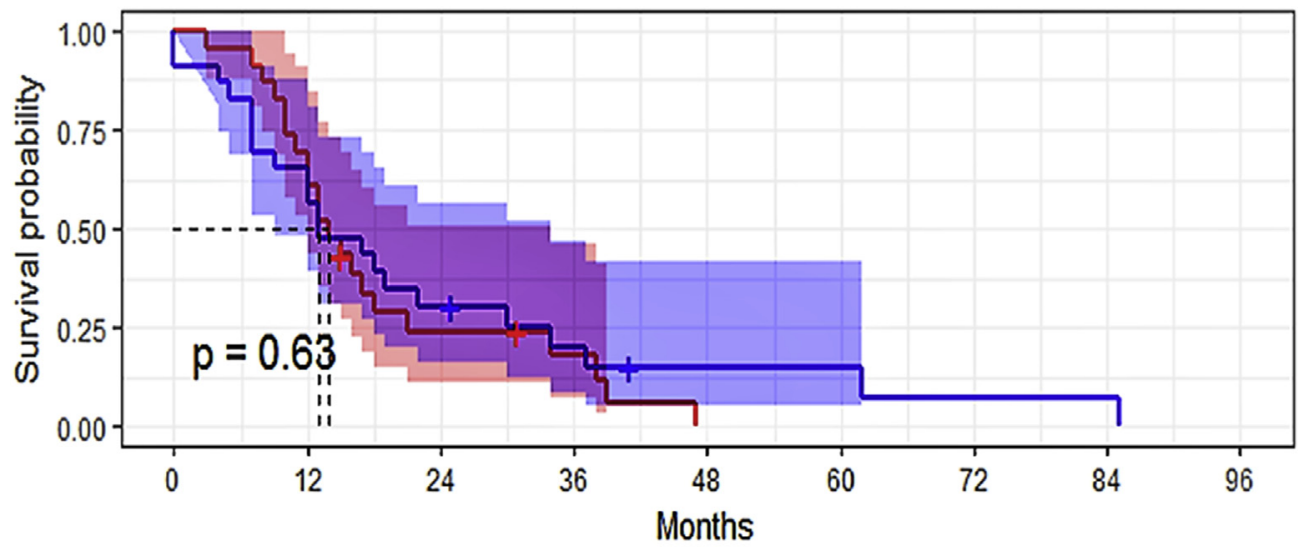

\begin{tabular}{|c|c|c|c|c|c|c|c|c|c|}
\hline \multirow{4}{*}{ 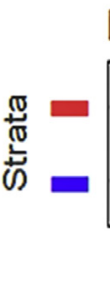 } & \multicolumn{9}{|c|}{ Number at risk } \\
\hline & 23 & 16 & 5 & 3 & 0 & 0 & 0 & 0 & 0 \\
\hline & 23 & 15 & 7 & 4 & 2 & 2 & 1 & 1 & 0 \\
\hline & 0 & 12 & 24 & 36 & 48 & 60 & 72 & 84 & 96 \\
\hline
\end{tabular}

FIGURE 2. Survival curve after propensity score matching undergoing macroscopic complete resection $(M C R)$ or not. There were 23 patients in each group. Median survivals of patients were 13.3 months (95\% confidence interval, 4.5-22.1 months) and 14.2 months (95\% confidence interval, 11.9 16.6 months), respectively $(P=.63)$. Two-year survival rate was $30 \%$ and $24 \%$, respectively, and 5 -year survival rate was $15 \%$ and $0 \%$, respectively. 

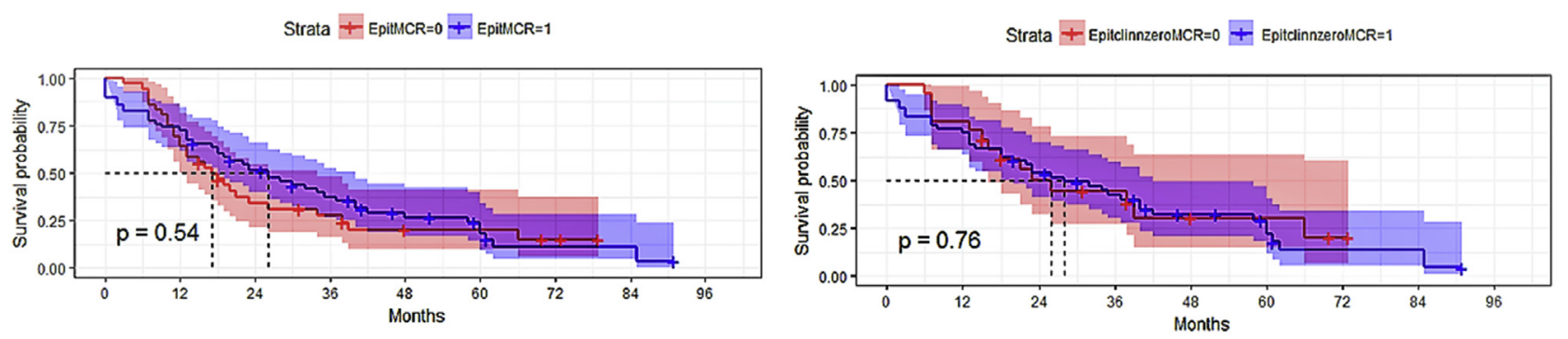

Number at risk
A

\begin{tabular}{|c|c|c|c|c|c|c|c|c|c|}
\hline \multirow{3}{*}{$\begin{array}{l}\text { 焉 } \\
\text { के }\end{array}$} & \multicolumn{9}{|c|}{ Numb } \\
\hline & 21 & 17 & 9 & 7 & 4 & 3 & 1 & 0 & 0 \\
\hline & 48 & 37 & 25 & 18 & 11 & 8 & 3 & 3 & 0 \\
\hline $\mathbf{R}$ & 0 & 12 & 24 & 36 & $\begin{array}{l}48 \\
\text { Mon }\end{array}$ & 60 & 72 & 84 & 96 \\
\hline
\end{tabular}

FIGURE 3. A, Survival comparison of patients undergoing macroscopic complete resection $(M C R)$ with epithelioid histology. Median survivals and 2-year and 5-year survival rates were 25.9 months (95\% confidence interval [CI], 16.1-35.7 months), 51\% (95\% CI, 45\%-58\%), and $21 \%$ (95\% CI, $15 \%-27 \%$ ) versus 17 months (95\% CI, 10.9-23.1 months), 34\% (95\% CI, 26\%-42\%), and 20\% (95\% CI, 13\%-27\%), respectively (P=.54). B, Survival comparison of MCR and non-MCR in patients with epithelioid histology and clinical N0 status. Median survivals, 2-year, and 5-year survival rates were 27.6 months (95\% CI, 13.2-42 months), 54\% (95\% CI, 47\%-61\%), and 25\% (95\% CI, 18\%-32\%) versus 23 months (95\% CI, $13.9-32.5$ months), 50\% (95\% CI, $39 \%-61 \%)$, and $30 \%(95 \% \mathrm{CI}, 19 \%-41 \%)$, respectively $(P=.76)$.

MCR was defined as no palpable or visible tumor left behind after surgical resection. However, this is very difficult to achieve in MPM due to the extent of tumor involvement. Lang-Lazdunski and colleagues ${ }^{13}$ reported an MCR rate of $56 \%$ in 102 patients following PD. In a multicenter international trial that analyzed neoadjuvant chemotherapy followed by EPP and optional hemithoracic irradiation, 151 patients were enrolled, 113 underwent EPP, and MCR was achieved in $96(54 \%$ of all patients and $85 \%$ of EPP patients). ${ }^{16}$

Two recent series focusing on multimodality treatment and MCR reported very favorable survival rates in highly selected subgroups of patients. Friedberg and colleagues ${ }^{17}$ reported results in 73 patients who underwent EPD and intraoperative photodynamic therapy over 8 years. Ninety patients were enrolled and $73(81 \%)$ had MCR. ${ }^{17}$ Median and recurrence free survivals were 3 and 1.2 years, respectively, in patients who underwent MCR. ${ }^{17}$ In patients who underwent EPP following accelerated hemithoracic irradiation median survival was 3 years. ${ }^{18}$ Fifty-nine of 62 patients completed the treatment scheme.

Sugarbaker and colleagues ${ }^{10}$ analyzed favorable prognostic features in $117(18 \%)$ patients who survived longer

TABLE 2. Number of 3-year survivors based on surgical technique $(P=.35)$

\begin{tabular}{lc}
\hline \multicolumn{1}{c}{ Patient } & Number of 3-y survivors $(\%)$ \\
\hline MCR $(\mathrm{n}=75)$ & $20(27)$ \\
Non-MCR $(\mathrm{n}=57)$ & $11(19)$ \\
Exploratory/diagnostic $(\mathrm{n}=22)$ & $3(14)$ \\
All patients $(\mathrm{n}=154)$ & $34(22)$ \\
\hline
\end{tabular}

$M C R$, Macroscopic complete resection. than 3 years out of 636 patients. Those patients were younger, predominantly female, more frequently had epithelioid histology, and had normal complete blood cell counts. ${ }^{10}$ Another multicentric study on EPP showed that $23 \%$ of patients lived longer than 3 years and similarly age and histology were significant prognostic factors followed by no history of asbestos exposure and metastatic/ normal lymph node ratio. ${ }^{9}$ In another study, patients who had stage III MPM and underwent EPD followed by chemoradiation, $37 \%$ survived longer than 3 years. ${ }^{19}$

The primary goal of surgery should be to obtain an MCR. This is advocated in a joint recommendation and several editorials/articles. ${ }^{1,5,6,20}$ When all visible/palpable tumors are removed, this should translate into a delay in time to recurrence and also a lower rate of local recurrence. One hundred sixty-nine patients who underwent EPP (heated intraoperative chemotherapy rate of $78 \%$ and $62 \%$ epithelioid histology), recurrences in ipsilateral hemithorax, contralateral hemithorax, abdomen, and other sites were exactly the same in 1997 and 2015 reports. ${ }^{21,22}$ Seventy percent of patients had locoregional, $50 \%$ had abdominal, and $35 \%$ had contralateral hemithoracic recurrence. When patients underwent EPD and postoperative chemoradiation, only locoregional recurrence occurred in $47 \%$ of patients, followed by distant and both $(14 \%$ each). ${ }^{19}$ In our previous report, ${ }^{3}$ when 2 practice periods were compared, the EPP-predominant period had more distant recurrences, whereas the PD-predominant period had more locoregional recurrences. Although an aggressive local treatment is applied, time to recurrence was 1.2 years in the report by Friedberg and colleagues. ${ }^{17}$ In patients who underwent accelerated neoadjuvant hemithoracic IMRT and EPP, only 30 patients out of 59 had recurrence and 
TABLE 3. Univariate and multivariate analyses for prognostic factors in macroscopic complete resection (MCR) and non-MCR cohorts $(\mathbf{n}=132)$

\begin{tabular}{|c|c|c|c|c|}
\hline \multirow[b]{2}{*}{ Variable } & \multicolumn{2}{|l|}{ Univariate } & \multicolumn{2}{|l|}{ Multivariate } \\
\hline & $\begin{array}{c}\text { Hazard ratio }(95 \% \text { confidence } \\
\text { interval) }\end{array}$ & $P$ value & $\begin{array}{c}\text { Odds ratio (95\% confidence } \\
\text { interval) }\end{array}$ & $P$ value \\
\hline Age & $1.026(1.006-1.046)$ & .01 & & NS \\
\hline $\begin{array}{l}\text { Gender } \\
\text { Female } \\
\text { Male }\end{array}$ & $\begin{array}{r}0.9105(0.623-1.326) \\
1.098(0.739-1.605)\end{array}$ & .62 & & \\
\hline $\begin{array}{l}\text { Side } \\
\text { Right } \\
\text { Left }\end{array}$ & $\begin{array}{l}0.896(0.608-1.309) \\
1.116(0.764-1.646)\end{array}$ & .57 & & \\
\hline $\begin{array}{l}\text { Histology } \\
\text { Epithelioid } \\
\text { Biphasic and sarcomatoid }\end{array}$ & $\begin{array}{l}0.603(0.336-0.885) \\
1.659(1.130-2.973)\end{array}$ & $<.001$ & $1.712(1.169-2.508)$ & .006 \\
\hline $\begin{array}{l}\text { Clinical T stage } \\
\mathrm{T} 1+\mathrm{T} 2 \\
\mathrm{~T} 3+\mathrm{T} 4\end{array}$ & $\begin{array}{l}0.679(0.455-1.017) \\
1.472(0.983-2.198)\end{array}$ & .002 & $\begin{array}{l}\text { T1 vs T3 + T4: } 0.082(0.011-0.683) \\
\text { T2 vs T3 + T4: } 0.778(0.507-1.193)\end{array}$ & $\begin{array}{l}.015 \\
\mathrm{NS}\end{array}$ \\
\hline $\begin{array}{l}\text { Clinical N stage } \\
\text { N0 } \\
\text { N1 + N2 } \\
\text { MCR } \\
\text { MCR } \\
\text { Non-MCR }\end{array}$ & $\begin{array}{l}0.537(0.298-0.742) \\
1.864(1.348-3.358) \\
1.131(0.774-1.670) \\
0.884(0.599-1.292)\end{array}$ & .0015 & & NS \\
\hline $\begin{array}{l}\text { Surgical/pathologic T stage } \\
\text { T1 + T2 } \\
\text { T3 + T4 }\end{array}$ & $\begin{array}{l}0.991(0.668-1.469) \\
1.009(0.681-1.496)\end{array}$ & .04 & & NS \\
\hline $\begin{array}{l}\text { Pathologic N stage } \\
\text { N0 } \\
\text { N2+NX }\end{array}$ & $\begin{array}{l}0.695(0.457-1.002) \\
1.439(0.998-2.188)\end{array}$ & .14 & & \\
\hline $\begin{array}{l}\text { Multimodality treatment } \\
\text { Chemotherapy } \\
\text { Chemoradiation }\end{array}$ & $\begin{array}{l}0.818(0.538-1.229) \\
1.222(0.814-1.859)\end{array}$ & .33 & & \\
\hline
\end{tabular}

Statistically significant values are in italics. $N S$, Not significant; $M C R$, macroscopic complete resection; $N x$, mediastinal lymph nodes not surgically evaluated.

ipsilateral hemithoracic recurrence was seen in 8 patients, whereas the remainder of the recurrences were in the contralateral chest or abdomen. ${ }^{18}$ Despite the changes in recurrence patterns, in most of the series this change does not translate into any survival advantage.

Our study has several limitations. It is a single-institution study that includes patients treated over 13 years with 2 different multimodality treatment protocols, which presents heterogeneity. The experience of the team has increased over the years, especially in the refinement of intraoperative surgical technique and multimodality treatment, which lead to a selection bias. The suitability of the patients for MCR was evaluated by a surgeon and, in cases of suspicion, by a thoracic radiologist. In patients who we accepted as non-MCR, some of the patients had minimal gross residual disease and also location of residual disease was not analyzed. We performed a power analysis, which showed that we needed at least 355 patients to demonstrate a $10 \%$ survival difference between MCR and non-MCR patients.
Although 5-year survival rates were similar between MCR and non-MCR patients, the differences in survival at 2 and 3 years may not show significance due to limited number of patients. In a review of published series, ${ }^{23}$ it was shown that addition of surgery to multimodality treatment protocols for MPM patients led to a survival extension of up to 9 months. Despite those limitations, in our patient cohort, overall, 2- and 5-year survival and proportion of patients who survived longer than 3 years were similar to those of the large series reported in the literature. ${ }^{8-10,12,24}$

\section{CONCLUSIONS}

In our cohort, MCR was not associated with improved survival after propensity score matching and in the favorable subgroups of patients with epithelioid histology and clinically nonmetastatic lymph nodes (Video 1). Larger numbers of patients should be analyzed to demonstrate the influence of MCR in patients with MPM. This result shows that we need to clearly define MCR and identify 


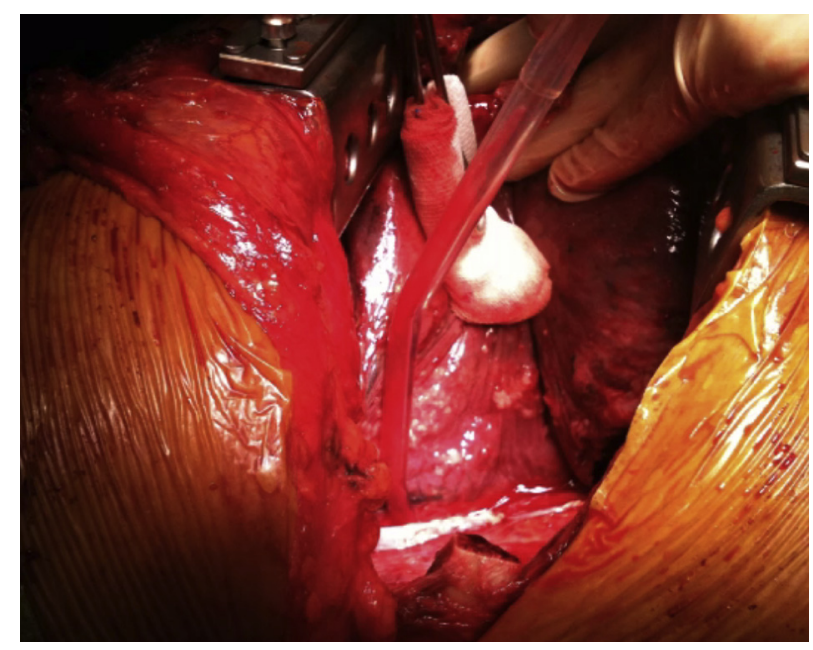

VIDEO 1. The video narrated by the first author and explains the aim and findings of the study. It is highlighted with surgical videos and survival curves of the study cohort. Video available at: http://www.jtcvsonline. org/article/S0022-5223(18)30304-0/fulltext.

subgroup of patients who would benefit from this principle because minimal versus extensive and location of gross residual disease may have different influences on survival.

\section{Webcast}

You can watch a Webcast of this AATS meeting presentation by going to: https://aats.blob.core.windows.net/ media/17AM/2017-05-03/RM312/05-03-17_Room312_ 0850_Batirel.mp4.

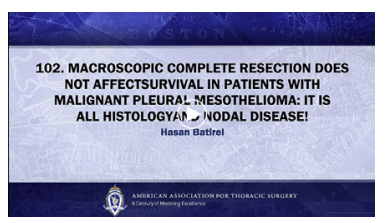

\section{Conflict of Interest Statement}

Authors have nothing to disclose with regard to commercial support.

The authors thank Sinan Uzun, MSc, for preparing the survival curves.

\section{References}

1. Rusch V, Baldini EH, Bueno R, De Perrot M, Flores R, Hasegawa S, et al. The role of surgical cytoreduction in the treatment of malignant pleural mesothelioma: meeting summary of the International Mesothelioma Interest Group Congress, September 11-14, 2012, Boston, Mass. J Thorac Cardiovasc Surg. 2013;145:909-10.

2. Rusch VW, Giroux D, Kennedy C, Ruffini E, Cangir AK, Rice D, et al. Initial analysis of the international association for the study of lung cancer mesothelioma database. J Thorac Oncol. 2012;7:1631-9.

3. Batirel HF, Metintas M, Caglar HB, Ak G, Yumuk PF, Yildizeli B, et al. Adoption of pleurectomy and decortication for malignant mesothelioma leads to similar survival as extrapleural pneumonectomy. J Thorac Cardiovasc Surg. 2016;151: 478-84.
4. Sharkey AJ, Tenconi S, Nakas A, Waller DA. The effects of an intentional transition from extrapleural pneumonectomy to extended pleurectomy/decortication. Eur J Cardiothorac Surg. 2016;49:1632-41.

5. Rice D, Rusch V, Pass H, Asamura H, Nakano T, Edwards J, et al. Recommendations for uniform definitions of surgical techniques for malignant pleural mesothelioma: a consensus report of the International Association for the Study of Lung Cancer International Staging Committee and the International Mesothelioma Interest Group. J Thorac Oncol. 2011;6:1304-12.

6. Sugarbaker DJ, Wolf AS. Surgery for malignant pleural mesothelioma. Expert Rev Respir Med. 2010;4:363-72.

7. Flores RM. Surgical options in malignant pleural mesothelioma: extrapleural pneumonectomy or pleurectomy/decortication. Semin Thorac Cardiovasc Surg. 2009;21:149-53.

8. Sugarbaker DJ, Richards WG, Bueno R. Extrapleural pneumonectomy in the treatment of epithelioid malignant pleural mesothelioma: novel prognostic implications of combined N1 and N2 nodal involvement based on experience in 529 patients. Ann Surg. 2014;260:577-82.

9. Spaggiari L, Marulli G, Bovolato P, Alloisio M, Pagan V, Oliaro A, et al. Extrapleural pneumonectomy for malignant mesothelioma: an Italian multicenter retrospective study. Ann Thorac Surg. 2014;97:1859-65.

10. Sugarbaker DJ, Wolf AS, Chirieac LR, Godleski JJ, Tilleman TR, Jaklitsch MT, et al. Clinical and pathological features of three-year survivors of malignant pleural mesothelioma following extrapleural pneumonectomy. Eur J Cardiothorac Surg. 2011;40:298-303.

11. Batirel HF, Metintas M, Caglar HB, Yildizeli B, Lacin T, Bostanci K, et al. Trimodality treatment of malignant pleural mesothelioma. J Thorac Oncol. 2008;3 499-504.

12. Sugarbaker DJ, Flores RM, Jaklitsch MT, Richards WG, Strauss GM, Corson JM et al. Resection margins, extrapleural nodal status, and cell type determine postoperative long-term survival in trimodality therapy of malignant pleural mesothelioma: results in 183 patients. J Thorac Cardiovasc Surg. 1999;117:54-65.

13. Lang-Lazdunski L, Bille A, Papa S, Marshall S, Lal R, Galeone C, et al. Pleurectomy/decortication, hyperthermic pleural lavage with povidone-iodine, prophylactic radiotherapy, and systemic chemotherapy in patients with malignan pleural mesothelioma: a 10-year experience. J Thorac Cardiovasc Surg. 2015; 149:558-66.

14. Bovolato P, Casadio C, Billè A, Ardissone F, Santambrogio L, Ratto GB, et al Does surgery improve survival of patients with malignant pleural mesothelioma? A multicenter retrospective analysis of 1365 consecutive patients. J Thorac Oncol. 2014;9:390-6.

15. Rintoul RC, Ritchie AJ, Edwards JG, Waller DA, Coonar AS, Bennett M, et al Efficacy and cost of video-assisted thoracoscopic partial pleurectomy versus talc pleurodesis in patients with malignant pleural mesothelioma (MesoVATS): an open-label, randomised, controlled trial. Lancet. 2014;384:1118-27.

16. Stahel RA, Riesterer O, Xyrafas A, Opitz I, Beyeler M, Ochsenbein A, et al. Neoadjuvant chemotherapy and extrapleural pneumonectomy of malignant pleural mesothelioma with or without hemithoracic radiotherapy (SAKK 17/04): a randomised, international, multicentre phase 2 trial. Lancet Oncol. 2015;16:1651-8.

17. Friedberg JS, Simone CB II, Culligan MJ, Barsky AR, Doucette A, McNulty S, et al. Extended pleurectomy-decortication-based treatment for advanced stage epithelial mesothelioma yielding a median survival of nearly three years. Ann Thorac Surg. 2017;103:912-9.

18. de Perrot M, Feld R, Leighl NB, Hope A, Waddell TK, Keshavjee S, et al Accelerated hemithoracic radiation followed by extrapleural pneumonectomy for malignant pleural mesothelioma. J Thorac Cardiovasc Surg. 2016;151: 468-73.

19. Bölükbas S, Eberlein M, Kudelin N, Demes M, Stallmann S, Fisseler-Eckhoff A, et al. Factors predicting poor survival after lung-sparing radical pleurectomy of IMIG stage III malignant pleural mesothelioma. Eur J Cardiothorac Surg. 2013;44:119-23.

20. Sugarbaker DJ. Macroscopic complete resection: the goal of primary surgery in multimodality therapy for pleural mesothelioma. J Thorac Oncol. 2006;1:175-6.

21. Baldini EH, Recht A, Strauss GM, DeCamp MM Jr, Swanson SJ, Liptay MJ, et al. Patterns of failure after trimodality therapy for malignant pleural mesothelioma. Ann Thorac Surg. 1997;63:334-8.

22. Baldini EH, Richards WG, Gill RR, Goodman BM, Winfrey OK, Eisen HM, et al Updated patterns of failure after multimodality therapy for malignant pleural mesothelioma. J Thorac Cardiovasc Surg. 2015;149:1374-81.

23. Utley M, Fiorentino F, Treasure T. Obtaining an upper estimate of the surviva benefit associated with surgery for mesothelioma. Eur J Cardiothorac Surg. 2010;38:241-4. 
24. Bölükbas S, Eberlein M, Fisseler-Eckhoff A, Schirren J. Radical pleurectomy and chemoradiation for malignant pleural mesothelioma: the outcome of incomplete resections. Lung Cancer. 2013;81:241-6.

Key Words: malignant pleural mesothelioma, macroscopic complete resection

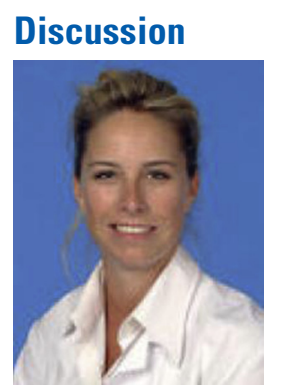

Dr I. Opitz (Zurich, Switzerland). First of all, I would like to thank the Society for this great opportunity to discuss your paper and to you, Professor Batirel, for providing the slides and the manuscript in advance.

Congratulations to this excellent presentation about the role of macroscopic complete resection (MCR) in mesothelioma patients. It is indeed discussed intensively in the mesothelioma community what is the precise role of surgery in these patients, in particular since publication of the UK MARS [United Kingdom, Mesothelioma and Radical Surgery] trial. As you have been stating correctly, the definition of MCR is highly variable and therefore it is most probably a very important determinant in your analysis. This leads me to my questions, which I will ask serially.

MCR was achieved in only $49 \%$ of patients. Even if you did not document prospectively in your database the location and volume of the disease left behind, do you have a feeling what were the limitations to obtain maximum cytoreduction, so at which site, and how much tumor did you leave behind?

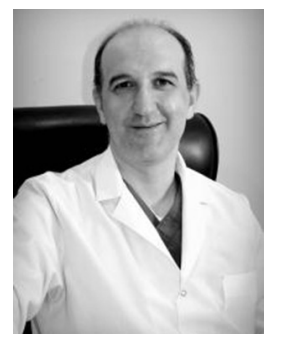

Dr H. F. Batirel (Istanbul, Turkey). Usually it is either mediastinal, apical, or sometimes the diaphragm. Our diaphragm removal rate was about $20 \%$ to $30 \%$. And the other thing is the non-MCR group patients also included those patients who didn't have any surgical resection, just had a small thoracotomy for a biopsy or a video-assisted thoracoscopic procedure or talc also. Initially they were evaluated for multimodality treatment, but found unresectable because of other factors.

Dr Opitz. Your comment about your diaphragm leads me to another question. You described in your paper that you resected the diaphragm also in the MCR group only if the diaphragm looked macroscopically normal (in 20\% to $30 \%)$. Did you confirm this by fresh frozen section?

Dr Batirel. No, we didn't do frozen section for those patients.

Dr Opitz. When you compared both groups, you showed a significantly higher number of patients receiving adjuvant treatment in your non-MCR group, and you also have a significantly higher number of 90-day mortalities in your MCR group. Besides this, you have a higher number of N2 patients in the MCR group.

Don't you think that these 3 factors might have contributed to the fact that you do not see a significant survival difference?

Dr Batirel. I think the N2s were similar in both groups.

Dr Opitz. Not significantly but higher.

Dr Batirel. Obviously this influences the survival, but the number of sarcomatoid and biphasic tumors were more frequent in the non-MCR group, so they also provide a poor prognostic factor. I think this balances both groups. But obviously we need a higher number of patients, especially to really see if there is any difference or not.

Dr Opitz. A final comment. Your survival difference in both groups was 8 months.

Dr Batirel. That's correct.

Dr Opitz. Although it is not statistically significant, which might be a problem of underpowered sample size, I would say that 8 months survival advantage is clinically meaningful for a mesothelioma patient cohort. I mean, our oncological colleagues are very excited for a 2-month survival difference in their treatment protocols. Thus, I would say that is a meaningful difference for these patients.

Finally, I have a recommendation for your group. Maybe you can use the Completeness of Cytoreduction Score for your protocols. We are using this in Zurich to document the amount of disease that is left behind. It is a score that was invented for peritoneal disease, and it is very helpful to quantify the amount of disease that is left behind.

Dr Batirel. Thank you very much. I'm sorry, I missed the first part of your last question.

Dr Opitz. It is actually more of a comment that it is clinically meaningful to have an 8-month survival.

Dr Batirel. Sorry. We did a power analysis, which showed that to demonstrate show a $10 \%$ survival difference we needed at least 355 patients enrolled. So obviously the data do not have enough power.

But what was striking for us was the 5-year survival rates were exactly the same. So it is most likely that the 5-year survival rate is more related to the biology of the disease and 2 to 3 years maybe influenced by the type of surgical resection or macroscopic complete resection removing the tumor completely.

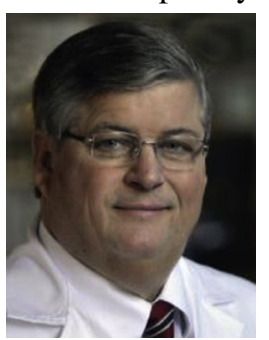

Dr D. Sugarbaker (Baylor, Tex). Hasan, this is a very interesting study. I would say, like in baseball, you get 3 strikes; it is all nodal disease, and what was the other thing?

Dr Batirel. Histology.

Dr Sugarbaker. Right, but the most important thing is tumor volume, and I understand you were doing EPPs throughout the period of time, right? 
Dr Batirel. That's correct.

Dr Sugarbaker. So obviously the indications for extrapleural pneumonectomy, as I think you learned them early on, are quite different than for pleurectomy and decortication. So if you are selecting patients for extrapleural pneumonectomy, undoubtedly they are a higher tumor volume, number 1 . Number 2, sarcomatoid and mixed tumors have a much lower $\mathrm{N} 2$ nodal rate than do epithelial tumors despite their aggressive nature; it is a biologic difference.

And the last thing I want to say is that in years 2 and 3, as I understand it, the MCR group had a better survival than the non-MCR group.

Dr Batirel. That's correct.

Dr Sugarbaker. So most patients after mesothelioma are lucky to live 3 years, and what your data showed was that MCR imparted to your cohort better survival in years 2 and 3. Is that how I understand it?

Dr Batirel. That's correct. Not statistically significant but better survival; it is 6 to 8 months better survival.

Dr Sugarbaker. Right. Well, as Dr Opitz just said, I would agree with that. But the point I am trying to make is, we are all going for 3-year survival in mesothelioma patients. Your data showed that there was an advantage to MCR, and then in the end there was no statistical difference, yet the power of your study really doesn't allow you to say much about 5-year survival. Would you agree?

Dr Batirel. I think we have a very similar 5-year survival rate when compared with the literature, because this is 150 patients, some of whom survived for 5 years.

Dr Sugarbaker. And the last 2 questions, I want to just echo what was said. You said you removed the diaphragm in $20 \%$ to $30 \%$ of patients.

Dr Batirel. I need to check, but I think that's 20\%. In extrapleural pneumonectomy patients, the diaphragm was removed in all.

Dr Sugarbaker. And why was that? What do you think the difference was that you removed the diaphragm in all of the extrapleural pneumonectomy group, because you don't necessarily have to unless there is gross disease in the diaphragm.

Dr Batirel. There was tumor in the diaphragm, obviously, more tumor in the diaphragm.

Dr Sugarbaker. The point I am trying to make is if you are resecting the diaphragm at a higher rate in your extrapleural pneumonectomy group and not in the pleurectomy and decortication group, it is because the pleurectomy and decortication group had a lower tumor volume.

Dr Batirel. That's correct. 